\title{
Abstract Animation and the Art of Sound
}

\author{
Joe Osmond \\ Birkbeck College, University of London \\ joebilby@yahoo.co.uk
}

\section{INTRODUCTION}

Searching for a true complementarity of music and visual art reflected John Whitney's desire to develop a methodology that would ensure that computer generated sound and visual imagery could be produced in a way that would go beyond all earlier attempts to simultaneously create an artwork based on a system that would equate individual colours with specific notes. Discussed in his book 'Digital Harmony' (Whitney 1980), Whitney argued that all composition in music was firmly based on a methodology that excluded improvisation and if a similarity of scale was applied to the use and development of colour, a system could be devised that met his objective of providing an agreed means of finally equated colour with sound, through computer programing.

But as a multi-sensory artist often using improvisational techniques to develop original compositions in sound, art, animation and digital applications, I question the validity of Whitney's theory, arguing that it is only through improvisational methodology that artists and musicians can truly explore the nature of their creativity.

\section{IMPROVISATIONAL CREATIVITY}

In my research, informed and supported by my own compositional work including "Birdsong for Prisoners" (EVA 2011), I have challenged both Whitney's view of compositional technique and his unease at the use of computer technology to create lightshows and synthesized music. While admitting that synthesized Bach and Captain Beefheart's lightshows may have appeared to diminish the potential of digital production, it cannot be ignored that their use created opportunities for other artists and composers to develop highly original and exciting work.

This liberation of technique through programing that eventually led to the ease of composition in both visual art and music has led me to reconsider Whitney's desire to achieve digital harmony and to explore the nature of how audiences perceive, experience and respond to sound and the visual image, with particular reference to abstraction.

Arguing that any attempt to create a true complementarity between music and the visual image, is subject to a number of variables that even the most advanced programing would find difficult to control, I have sought to identify both the potential and the constraints that Whitney's theory of digital harmony presents. This has led to further research into the problems caused by the instability of colour transmitted via a computer screen, drawing comparisons with the colour variations experienced by designers working in other light based fields including stained glass in synagogues and the work of American light artist James Turrell. (Turrell 2010)

My research has also been concerned with identifying a similar instability in sound, with particular reference to improvisation in jazz and the use of notes that may not be easily notated in manuscript form.

Challenging Whitney's desire for 'Digital Harmony' may still be viewed as a 'work in progress' as I continue research into the nature and structure of creativity and the role of 'chance' in the development of compositions in sound and abstraction.

\section{REFERENCES}

Osmond, J. (2011) Birdsong for Prisoners: EVA 2011, London, $6^{\text {th }}-8^{\text {th }}$ July, BCA, Swindon.

Turrell, J. (2010) London Exhibition:

http://www.gagosian.com/exhibitions/2010-1013_james-turrell/

Whitney, J. (1980) Digital Harmony: On the Complementarity of Music and Visual Art: Byte Books/McGraw-Hill, Peterborough New Hampshire 